\title{
CONTRIBUIÇÃO PARA A RECONSTRUÇÃO DE PALEOPERFIS DE ALTERAÇÃO NO PLANALTO DE PALMAS/ÁGUA DOCE - SUL DO BRASIL
}

\author{
JULio CESAR PAISANI ${ }^{1}$ \\ MARGA ELIZ PONTELLI ${ }^{2}$ \\ MARCIA REgina CALEGARI ${ }^{3}$ \\ Universidade Estadual do Oeste do Paraná
}

\begin{abstract}
Resumo: O presente artigo visa reconstruir paleoperfis de alteração a partir dos sedimentos de depósito de articulação encosta/calha fluvial no Planalto de Palmas/Água Doce durante os 41.000 anos AP. Foram empregadas análises granulométricas, químicas e mineralógicas da fração argila em seção previamente caracterizada. Reconheceram-se quatro momentos distintos de intemperismo na área de estudo: a) antes de 41.000 anos AP se desenvolveram dois momentos ainda não identificados, um de monossialitização e outro de alitização; b) entre 41.000 a 25.000 anos AP registra-se a passagem para acidólise; c) entre 25.000 e 11.000 anos AP houve mudança de processo retornando a hidrólise; e d) nos últimos 11.000 anos, os materiais mantiveram o registro geoquímico das fases anteriores.
\end{abstract}

Palavras-chave: Colúvios; Paleossolo; Paleointemperismo; Quaternário Continental.

\footnotetext{
${ }^{1}$ Professor na Universidade Estadual do Oeste do Paraná. Mestre e doutor em Geografia pela UFSC. Contato: juliopaisani@hotmail.com.

${ }^{2}$ Professora na Universidade Estadual do Oeste do Paraná. Mestre e doutora em Geografia pela UFSC. Contato: mepontelli@ hotmail.com.

${ }^{3}$ Professora na Universidade Estadual do Oeste do Paraná. Mestre em Geografia pela UFSC e doutora em Solos pela ESALQ. Contato: marciareg_calegari@hotmail.com.
} 


\title{
CONTRIBUTION FOR THE RECONSTRUCTION OF PALAEOPROFILE OF WEATHERINGIN PALMAS/ÁGUA DOCE PLATEAU - SOUTH BRAZIL
}

\begin{abstract}
The current article aims to rebuild weathering palaeoprofiles alteration from alluvial/colluviums deposits on Palmas /Água Doce plateau - South of Brazil during the 41.000 thousands years BP. It has been applied granolumetric, chemical and mineralogical analysis of the clay fraction in section previously characterized. It has been acknowledged four different stages of weathering in the study area: a) before 41.000 years BP, two stages not dated yet were observed, one of mosialitization and other of alitization; b) between 41.000 to $25.000 \mathrm{BP}$, a change toward partial acidolysis is identified; and d) after 11.000 years the materials maintained the geochemical records of previous phases.
\end{abstract}

Keywords: Colluvium; Palaeosoil; Palaeowethering; Continental Quaternary.

\section{Introdução}

A análise da evolução da paisagem tem revelado que as formações superficiais se constituem em importantes registros dos processos ocorridos ao longo do tempo. Nesse sentido, perfis de alteração podem ser entendidos como registro de condições ambientais específicas que favorecem a ação do intemperismo e da pedogênese, ao passo que depósitos sedimentares registram períodos de erosão ao longo de encostas. Enquanto o primeiro demonstra uma estabilidade frente aos processos morfogenéticos, o segundo retrata a instabilidade do ambiente por meio de fenômenos de degradação e agradação, como propõe o conceito de K-ciclos de Butler (GERRARD, 1992).

As formações superficiais quaternárias, por registrarem esses ciclos, são consideradas poligenéticas. Historicamente, a Sedimentologia tem dado atenção aos períodos de instabilidade e identificado os processos deposicionais. Os períodos de estabilidade, em geral, são entendidos como fases geradoras de material a ser removido na fase seguinte. No entanto, não basta somente reconhecer as fases de estabilidade do ambiente, mas, sim, saber quais as condições ambientais que vigoravam durante o período de estabilidade. Assim, os paleossolos são vistos como os principais fornecedores destas informações (RETALLACK, 1997), porém nem sempre se mantêm preservados na paisagem. Por vezes, a constante repetição dos fenômenos de erosão atinge todo o perfil de intemperismo, apagando os registros da fase de estabilidade precedente. Outras vezes, a baixa intensidade da erosão não é suficiente para apagar/alterar os registros, permitindo que sejam reconhecidos os processos responsáveis pelo intemperismo/pedogênese de uma determinada área.

Na paisagem do sudoeste do Estado do Paraná (PR) e do noroeste do Estado de Santa Catarina (SC), mantida pelos derrames vulcânicos da Formação Serra Geral, existem superfícies que apresentam diferentes graus de renovação dos perfis de intemperismo (PAISANI et al., 2008; 2013a), sendo menos intensa nas superfícies que se localizam na direção oeste desta área. Até o momento, percebemos que 
predominam ao longo das superfícies perfis de alteração com diferentes espessuras e graus de evolução de Nitossolos e Latossolos, mostrando a ocorrência de situação geoquímica de hidrólise parcial evoluindo para total (RODRIGUES, 2011; PONTELLI et al., 2011). O mesmo não é possível de ser identificado no extremo leste dessa área, Planalto de Palmas/Água Doce, onde se registram formações superficiais constituídas por sedimentos fácies coluvial, colúvio-aluvial e aluvial pedogeneizados (PAISANI et al, 2012; GUERRA; PAISANI, 2012).

A compreensão da evolução da paisagem, utilizando-se das formações superficiais como registros dos processos ocorridos ao longo do tempo, fundamenta os trabalhos do grupo de pesquisa Gênese e Evolução de Superfícies Geomórficas e Formações Superficiais, cadastrado no $\mathrm{CNPq}$ e formado na Universidade Estadual do Oeste do Paraná (UNIOESTE). As condições ambientais responsáveis pelos períodos de instabilidade da paisagem do Planalto de Palmas/Água Doce estão em estudo. Até o momento os resultados obtidos a partir dos registros sedimentares permite inferir fases de estabilidade (predomínio de pedogênese) e instabilidade (predomínio de morfogênese) nos 41.000 anos AP (PAISANI et al., 2014).

Sabemos que durante o final do Pleistoceno Superior, sobretudo nos estágios isotópicos marinhos (EIM) 3 e 2, o sistema fluvial de baixa ordem hierárquica e o ambiente de encosta se encontravam em equilíbrio dinâmico (PAISANI et al., 2012; GUERRA; PAISANI, 2013). A partir da passagem para o EIM 1 ocorreu intensa morfogênese das encostas e colmatação dos fundos de vale das bacias hidrográficas de baixa ordem hierárquica, que perdurou até cerca de 1.000 anos AP. Coincidindo com esta fase, processou-se a migração do divisor de águas regional para o norte, com consequente desmantelamento das bacias de $1^{\mathrm{a}}$ ordem, reorganização da hierarquia da rede de drenagem e inversão de relevo (PAISANI et al., 2012; 2013b; 2014).

Algumas dúvidas ainda persistem a respeito das propriedades dos materiais de origem dos sedimentos que colmataram os vales de baixa ordem hierárquica. Não se sabe se foi o pedon ou níveis de alteração que forneceram material para os depósitos, nem se eles exibiam processos pedogeoquímicos similares aos das condições climáticas atuais. Neste contexto, a presente pesquisa visa contribuir para elucidar tais questões e reconstruir os paleoperfis de alteração a partir dos sedimentos de depósito de articulação encosta/calha fluvial no Planalto de Palmas/Água Doce durante os 41.000 anos AP.

\section{O Planalto de Palmas/Água Doce}

O Planalto Palmas/Água Doce se encontra na região Sul do Brasil e corresponde a uma unidade morfológica inscrita na seção morfoestrutural regional conhecida 
como Planalto Basáltico da Bacia do Paraná (ALMEIDA, 1956) (ver Figura 1). Essa unidade morfoestrutural é mantida por derrames vulcânicos de idade EoCretácea que, em conjunto, correspondem à Formação Serra Geral (SCHNEIDER et al., 1974). Embora predominem derrames de natureza básica nessa formação, registram-se no Planalto de Palmas/Água Doce derrames de natureza ácida que correspondem ao membro Palmas (NARDY et al., 2008).

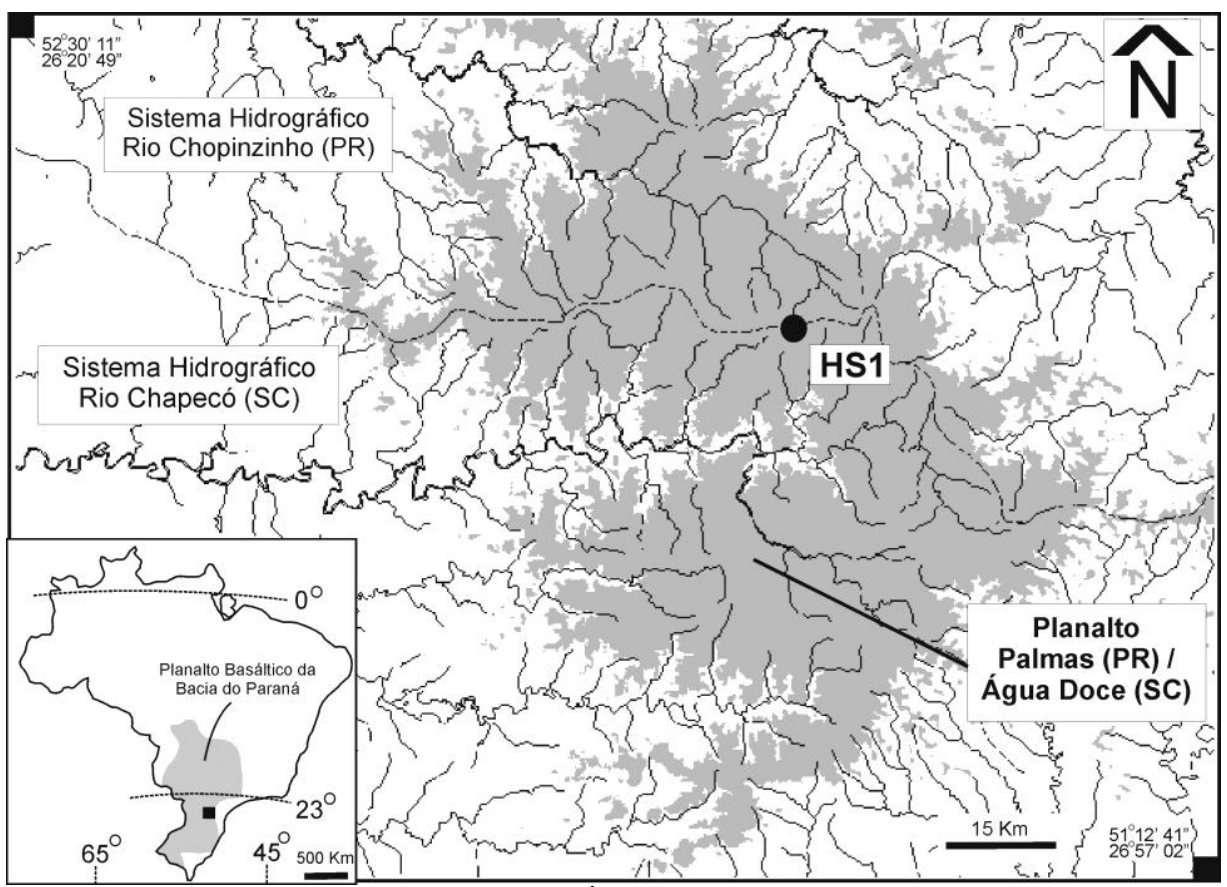

Figura 1: Planalto de Palmas (PR) / Água Doce (SC).

HS1: Seção estratigráfica guia dos registros morfodinâmicos da área (adaptado de PAISANI et al., 2012).

Até o momento, duas litofácies de rochas vulcânicas sobrepostas foram identificadas no membro Palmas neste planalto. Uma delas é formada por riolitos constituídos principalmente por quartzo e cristobalita (28-38\%), ortoclásio (23$37 \%$ ), plagioclásio (17-36\% - Albita > Anortita), hiperstênio (5-8\%), coríndon $(<5 \%)$, magnetita $(\geq 2 \%)$, diopsídio $(<2 \%)$, ilmenita $(<2 \%)$ e apatita $(>1 \%)$ (CHMYZ, 2013). Subjacentes aos riolitos ocorrem derrames hidrotermais fortemente intemperizados (LIMA, 2013) (Figura 2). Essas duas fácies exibem inúmeros afloramentos na área em estudo e, nem sempre, apresentam relação direta com as morfologias recorrentes na área, tais como relevos residuais e ombreiras em fundos de vales. 


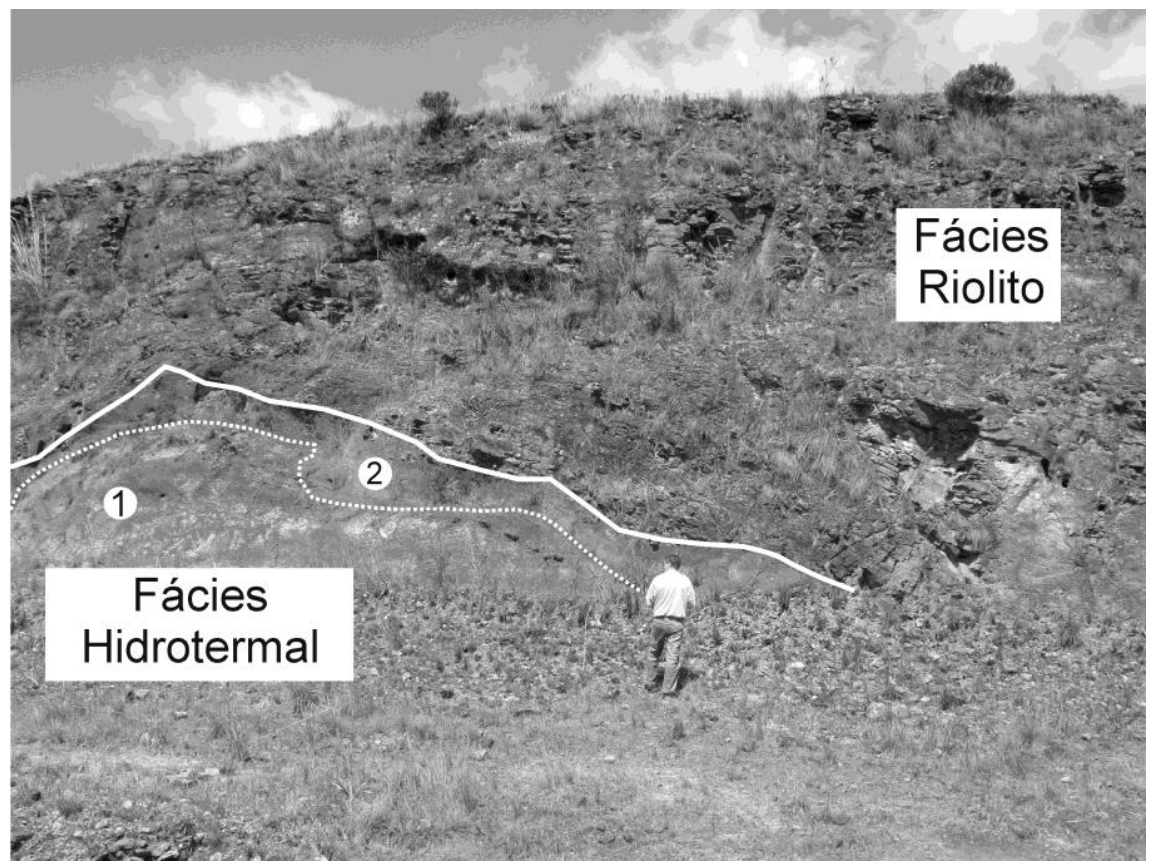

Figura 2: Litofácies encontradas na área de estudo. Nota-se que a fácies hidrotermal exibe dois níveis, um predominantemente caolinizadas em matriz avermelhada (1) e outro em contato com riolito homogêneo de coloração laranja (2).

Além dessas morfologias, registram-se na área relevos residuais alongados de topo suavemente convexo, comuns nas cotas acima de $1.300 \mathrm{~m}$ de altitude. Tais relevos correspondem a remanescentes da superfície de cimeira, designados de Superfície 1 (PAISANI et al., 2008; 2014). Já o nível topográfico que individualiza o Planalto de Palmas/Água Doce equivale a um remanescente de superfície incompletamente aplainada, denominada de Superfície 2, que se encontra entre $1.200 \mathrm{~m}$ e $1.300 \mathrm{~m}$ de altitude (PAISANI et al., 2008; 2013a). Essas superfícies mantêm importante divisor de águas regional que, na área em estudo, separa as águas que drenam para o sistema hidrográfico do rio Chopinzinho, ao norte, daquelas que drenam para o sistema hidrográfico do rio Chapecó, ao sul. Estes rios são, respectivamente, afluentes dos rios Iguaçú e Uruguai. Esse divisor de águas configura-se como limite político entre os Estados do Paraná e de Santa Catarina.

As superfícies incompletamente aplainadas, colinas, ombreiras e fundos de vales exibem formações superficiais pouco profundas, constituídas por colúvios, alúvios e paleossolos, além de localmente Neossolos Regolíticos e Litólicos com horizonte A húmico. 
O clima predominante é o temperado sempre úmido, com 5 geadas por ano (cf. na classificação de Köppen), caracterizado por $1.590 \mathrm{~mm}$ anuais de pluviosidade bem distribuída ao longo do ano e estações marcadas por contrastes de temperatura (PAISANI et al., 2014).

\section{Seção estratigráfica amostral}

As informações mais completas a respeito do registro estratigráfico obtidas até o momento no Planalto de Palmas/Água Doce foram encontradas na seção HS1. Tal seção se caracteriza como guia e exibe cerca de $50 \mathrm{~m}$ de extensão lateral por aproximadamente $2,7 \mathrm{~m}$ de altura. Encontra-se em situação de interflúvio na unidade geomórfica identificada como Superfície Aplainada 2 (PAISANI et al., 2008), a qual constitui-se de uma superfície de erosão que cruza duas fácies litológicas distintas, riolito e riolito hidrotermalizado (ver Figura 3). O fato de atualmente a HS1 se encontrar em um interflúvio e guardar registros de que no passado este local correspondia a fundo de vale de um paleocanal de segunda ordem hierárquica, foi fundamental para Paisani et al. (2012) reconstruírem o quadro evolutivo da área.

A descrição em campo da seção foi realizada por Paisani et al. (2012; 2013b), que identificaram sete unidades litológicas - sendo duas aluviais, uma colúvioaluvial, três coluviais e uma tecnogênica. Uma das unidades coluviais e a unidade colúvio-aluvial mostraram-se pedogenizadas com desenvolvimento de horizontes A húmicos (ver Tabela 1). Recentemente essas unidades foram reclassificadas seguindo critérios pedoestratigráficos (PAISANI et al., 2014). As datações revelaram que essas unidades litológicas e pedológicas se desenvolveram nos últimos 41.000 anos AP (Figura 3). 


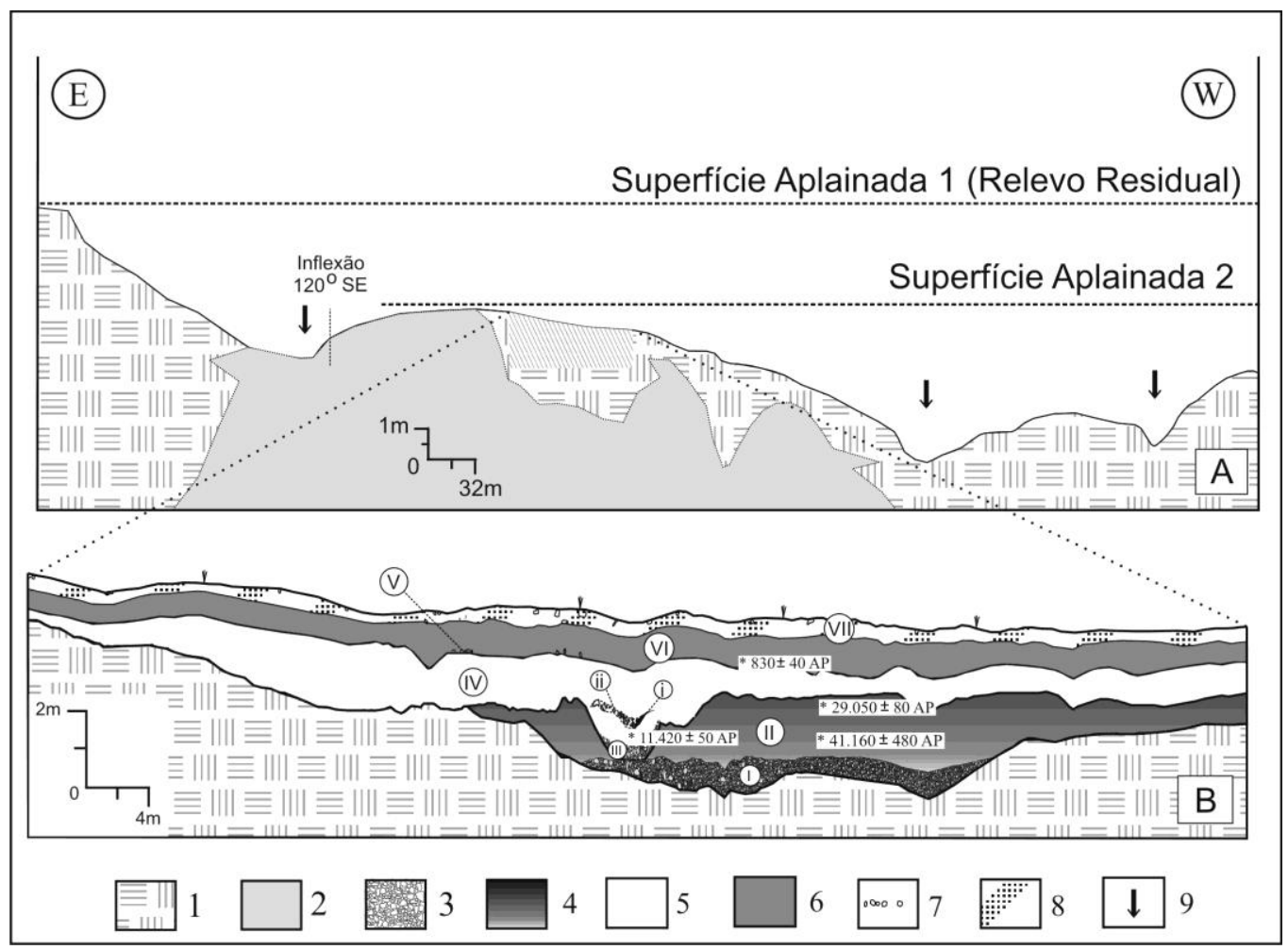

Figura 3: Reprodução da seção lito-pedoestratigráfica (adaptado de PAISANI et al., 2012).

Legenda: (A) Perfil topográfico e geológico. (B) Seção estratigráfica com identificação das unidades por algarismos romanos da base para o topo. Nota-se paleossolo (unidade litológica II pedogenizada) truncado por canal colmatado (unidades III e IV). 1: riolito. 2: fácies intemperizada. 3: alúvio cascalho oligomítico lamoso maciço com clastos suportados. 4: colúvio-aluvial lama maciça pedogenizada com horizonte hidromórfico. 5: colúvio lama maciça. 6: colúvio lama maciça pedogenizado. 7: colúvio retrabalhado cascalho oligomítico lamoso maciço com matriz suportada disposto como linha de pedras descontínua. 8: tecnogênico lama cascalhenta maciça com matriz suportada oligomítica. 9: canal intermitente. I, II, III...: unidades litoestratigráficas. i: lama maciça. ii: cascalho oligomítico lamoso maciço com matriz suportada. Essas unidades foram reclassificadas seguindo critérios pedoestratigráficos por Paisani et al. (2014). 


\begin{tabular}{|c|c|c|c|c|c|c|c|c|}
\hline \multicolumn{6}{|c|}{ Litoestratigrafia } & \multicolumn{3}{|c|}{ Pedoestratigrafia } \\
\hline $\mathrm{U}_{\mathrm{n}}$ & $\begin{array}{l}\mathrm{E} \\
\mathrm{m}\end{array}$ & $\begin{array}{l}\mathrm{C} \\
\mathrm{o}\end{array}$ & Fácies* & $\mathrm{C}_{\mathrm{FG}}$ & $\mathrm{C}_{\mathrm{M}}$ & $\begin{array}{l}\mathrm{U} \\
\mathrm{n}\end{array}$ & $\mathrm{C}_{\mathrm{p}}$ & Obs \\
\hline $\begin{array}{l}\text { VI } \\
\text { I }\end{array}$ & 15 & $\mathrm{e}$ & $\begin{array}{c}{ }_{\mathrm{o}} \mathrm{m}_{1} \mathrm{GyM} \\
-\mathrm{T}\end{array}$ & $\begin{array}{c}10 \mathrm{YR} \\
4 / 4, \\
\text { pi, cx } \\
0,2 \\
\mathrm{~cm}, \\
\mathrm{md} \\
\mathrm{sm}-\mathrm{sg}\end{array}$ & $\begin{array}{c}\text { D- } \\
\text { III, } \\
\text { D- } \\
\text { IV, } \\
\text { gr lit } \\
+ \text { cc }\end{array}$ & - & - & - \\
\hline VI & 55 & $\mathrm{a}$ & $\mathrm{mM}-\mathrm{C}$ & - & $\begin{array}{l}\text { D- } \\
\text { IV, } \\
\text { D-V, } \\
\text { gr lit } \\
+\mathrm{cc}\end{array}$ & 2 & $\begin{array}{c}7.5 \\
\mathrm{YR} \\
2.5 / 1 \\
, \mathrm{bs}, \\
\mathrm{pg}, \\
\mathrm{p}, \mathrm{fb}, \\
\mathrm{tcs}\end{array}$ & - \\
\hline $\mathrm{V}$ & 5 & $\mathrm{e}$ & $\begin{array}{c}{ }_{\mathrm{o}} \mathrm{m}_{1} \mathrm{MyG} \\
-\mathrm{C}\end{array}$ & $\begin{array}{l}\text { bxs, } \\
\text { pi, cx } \\
1,5-2 \\
\mathrm{~cm}, \\
\mathrm{md} \\
\mathrm{sm}\end{array}$ & $\begin{array}{l}\text { D- } \\
\text { IV, } \\
\text { D-V, } \\
\text { gr lit } \\
+ \text { cc }\end{array}$ & - & - & - \\
\hline IV & 75 & $\mathrm{a}$ & $\mathrm{mM}-\mathrm{C}$ & $\begin{array}{l}7.5 \\
\text { YR } \\
4 / 3 \text {, } \\
\text { ped, }\end{array}$ & $\begin{array}{l}\text { D- } \\
\text { IV, } \\
\text { gr lit } \\
+\mathrm{cc}\end{array}$ & - & - & $\begin{array}{c}2 \text { lentes } \\
\text { inscritas } \\
\mathrm{mM}-\mathrm{C} \text { e } \\
{ }_{\mathrm{o}} \mathrm{m}_{2} \mathrm{MyG} \\
-\mathrm{C}\end{array}$ \\
\hline III & 20 & ec & $\begin{array}{c}{ }_{\mathrm{o}} \mathrm{m}_{2} \mathrm{MyG} \\
-\mathrm{A}\end{array}$ & $\begin{array}{l}\text { bxs, } \\
\text { pi, cx } \\
1,5 \mathrm{~cm} \\
, \text { md } \\
\text { sg }\end{array}$ & $\begin{array}{c}\text { D- } \\
\text { III, } \\
\text { gr lit } \\
+ \text { cc }\end{array}$ & 1 & $\begin{array}{c}7.5 \\
\mathrm{YR} \\
3 / 2, \\
\mathrm{bs}, \\
\mathrm{mp}, \\
\mathrm{pp}, \\
\mathrm{fb}, \\
\mathrm{mh}, \\
\mathrm{tcs}\end{array}$ & $\begin{array}{c}\text { depleção } \\
\text { Fe }\end{array}$ \\
\hline II & 80 & $\mathrm{e}$ & $\mathrm{mM}-\mathrm{AC}$ & - & $\begin{array}{c}\text { D- } \\
\text { IV,D } \\
-V, E- \\
\text { IV,E- } \\
V, \text { gr } \\
\text { cc }\end{array}$ & - & - & - \\
\hline $\mathrm{I}$ & 45 & $\mathrm{ec}$ & ${ }_{\mathrm{o}} \mathrm{m}_{2} \mathrm{MyG}$ & bxs, & B-II, & & & \\
\hline
\end{tabular}




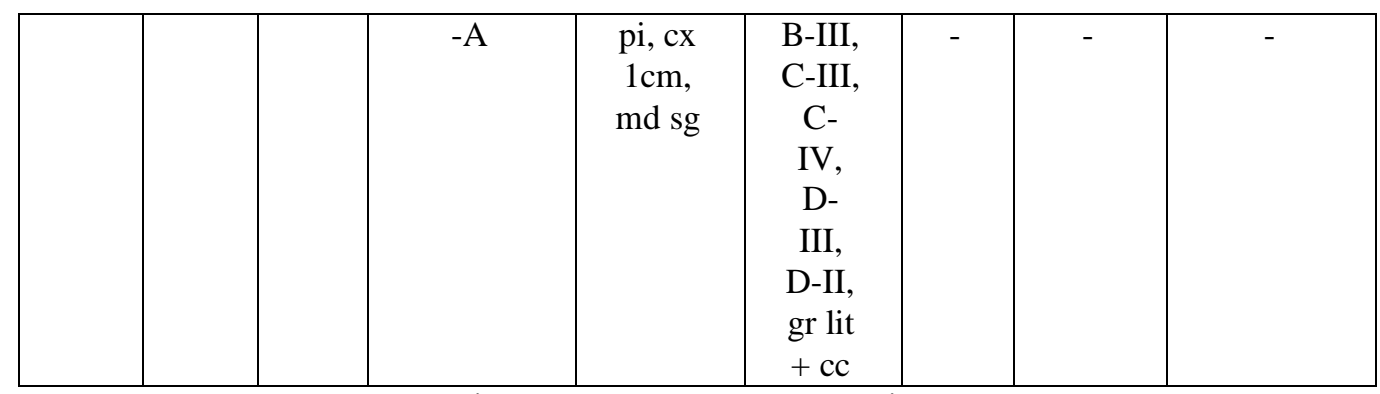

Tabela 1: Principais características das unidades estratigráficas da HS1 (PAISANI et al., 2013b).

Legenda: Un: unidade. Em: espessura média (cm). Co: contato. *baseado em Ghibaudo (1992). CFG: características da fração grossa. CM: características da matriz. A: aluvial. AC: colúvio-aluvial. C: coluvial. T: tecnogênica. M: lama. GyM: lama cascalhenta. MyG: cascalho lamoso. O: oligomítico (fragmentos líticos da fácies riolito + calcedônia e clastos residuais silicosos da fácies intemperizada). m: maciça. . m1: maciça com matriz suportada. m2: maciço com clastos suportados. a: abrupto. e: erosivo. ec:erosivo com incisão de canal. bxs:baixa esfericidade/subarredondado. pi: parcialmente intemperizado. cx: córtex de alteração. md: moda. sg: seixo grosso. sm: seixo médio. gr: grânulo. cc: calcedônia. lit: litorrelíquias do riolito. ped: pedorrelíquias paleohorizonte A. B-II: areia siltosa. B-III: areia argilosa. C-III: lama arenosa siltosa. C-IV: lama arenosa argilosa. D-II: lama levemente arenosa muito siltosa. D-III: lama levemente arenosa siltosa. D-IV: lama levemente arenosa argilosa. D-V: lama levemente arenosa muito argilosa. E-IV: argila siltosa. E-V: argila levemente siltosa. bs: blocos subangulares. pg: pegajoso. mp :muito pegajoso. pp: pouco plástico. p: plástico. fb: forte bioturbação. mh: manchas de hidromorfia. tcs: transição clara sinuosa.

\section{Método}

O método empregado pressupõe que as características granulométricas, químicas e mineralógicas da fração argila podem indicar: a) materiais de origem correspondentes a horizontes de solo ou níveis de alteração; b) o estado evolutivo dos perfis de intemperismo; e, c) processos pedogeoquímicos atuantes na área nos 41.000 anos AP.

\section{Granulometria da matriz das unidades}

A granulometria da matriz das unidades litológicas foi determinada no laboratório de Análise de Formações Superficiais da UNIOESTE, Campus de Francisco Beltrão, por meio dos clássicos procedimentos sedimentológicos: peneiramento para fração grossa e pipetagem para fração fina, com separação via úmida entre ambas (SUGUIO, 1973). Essa determinação foi realizada visando definir classes texturais e verificar o grau de semelhança entre as fácies 
sedimentares e a isalterita do riolito (DELVIGNE, 1998) e da fácies riolito hidrotermal.

Coletamos um total de 37 amostras verticalmente, a cada $10 \mathrm{~cm}$, em duas linhas verticais ao longo da seção. Para caracterizar a isalterita do riolito e da fácies intemperizada, utilizamos amostras de outras seções. Os intervalos granulométricos seguiram a escala de Wentworth, enquanto a classificação textural se baseou no diagrama triangular proposto por Flemming (2000) - utilizado na caracterização de unidades coluviais em outras áreas de estudo na região (PAISANI; GEREMIA, 2010).

\section{Química total}

O método mais utilizado para descrever a intensidade do intemperismo é a análise química total (THOMAS, 1994). Foram determinados os 10 principais óxidos contidos na matriz de cada unidade levantada, bem como em uma amostra da isalterita e da rocha fresca do riolito, onde a seção foi descrita. Um total de 7 amostras foram submetidas a fluorescência de raio-X pelo Laboratório de Fluorescência de Raio-X e de Química \& ICP, do Instituto de Geociências da USP. A classificação litológica da rocha fresca foi conferida, estabelecendo-se a razão álcalis- súlica no clássico diagrama TAS. Em relação a todas as mostras, estabelecemos as razões $\mathrm{SiO}_{2} / \mathrm{Al}_{2} \mathrm{O}_{2}$ e $\mathrm{SiO}_{2} /\left(\mathrm{Al}_{2} \mathrm{O}_{2} / \mathrm{Fe}_{2} \mathrm{O}_{3}\right)$, respectivamente os índices Ki e Kr.

\section{Mineralogia das argilas da aração fina}

A mineralogia das argilas da fração fina, identificação de argilossilicatos, foi empregada visando verificar o produto do intemperismo. Essa determinação foi realizada em 5 amostras representativas das unidades que correspondem às fácies deposicionais - exceto a fácies tecnogênica -, bem como à isalterita do riolito e à fácies hidrotermal. A identificação foi realizada no Laboratório de Difração de Raio-X da UFRGS, por meio da técnica de difração de raio-X com os métodos natural, glicolada e calcinada. As fases mais expressivas do difratograma foram interpretadas por técnicos do laboratório. 


\section{Resultados e Discussão}

\section{Classificação textural}

A classificação textural foi empregada para verificar o grau de similaridade desta característica da matriz dos sedimentos das unidades identificadas na seção HS1 em relação à isoalterita do riolito e da fácies hidrotermal.

As unidades aluviais (I e III) são semelhantes quanto à litofácies, porém apresentam variabilidade na textura da matriz (ver Figura 4). A matriz da unidade III é constituída de lama levemente arenosa (75-95\% lama) e a matriz da unidade I é composta por variabilidade significativa, sendo de lama levemente arenosa, lama arenosa $(50-75 \%)$ a areia lamosa $(25-50 \%$ lama), como mostra a Figura 4. Esta diferenciação está relacionada apenas à espessura das unidades, em que a unidade III, por ser mais delgada, exibiu pouca variabilidade vertical. Quando se compara a textura da isalterita do riolito e da fácies hidrotermal, com a textura da unidade I, constata-se que esta é a única que apresenta matriz com textura semelhante àquela das duas fácies litológicas, face os maiores percentuais de silte.

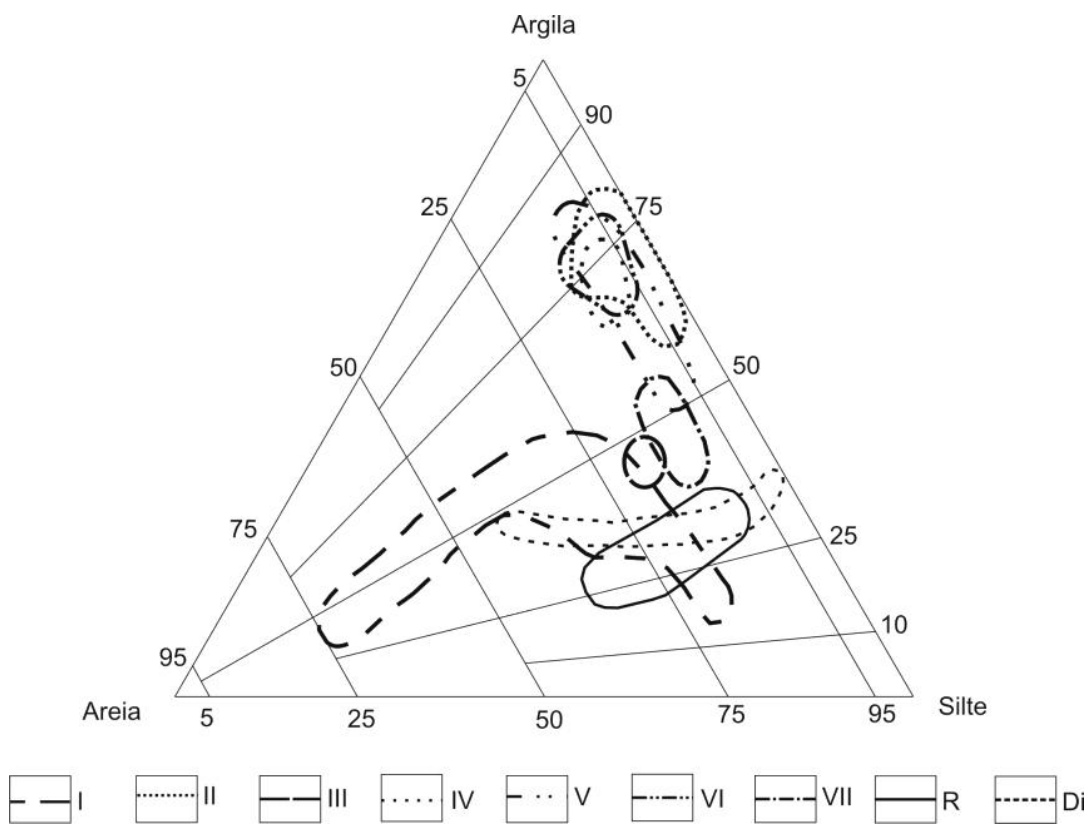

Figura 4: Diagrama ternário de Flemming contendo a textura da matriz das unidades litoestratigráficas. Os números indicam a nomenclatura das unidades. R: isalterita da fácies riolito. Di: fácies hidrotermal subjacente ao riolito. 
Em relação à matriz das unidades II (colúvio-aluvial pedogenizada), IV (coluvial), V (coluvial - linha de pedras) e VI (coluvial pedogenizada), constatamos que era constituída de lama levemente arenosa a lama, e se encontra em um campo bem definido do diagrama de Flemming - entre 90 e $50 \%$ de argila (Figura 4). Este dado mostra que as unidades coluviais e colúvio-aluviais não apresentaram variações que subsidiasse individualização delas a partir da classe textural. Por outro lado, com a comparação entre o campo de concentração da textura das unidades coluviais e o das isalteritas dos dois derrames percebe-se significativas diferenças, conforme se vê na figura acima.

Enfim, a unidade VII, tecnogênica apresenta matriz de levemente arenosa argilosa a arenosa siltosa, se individualizando em relação às demais fácies e às isoalteritas de ambas as fácies de derrames (ver Figura 4).

A classificação textural mostrou a existência de diferenças significativas entre as unidades aluviais e coluviais, mas não apresentou diferenças entre as unidades coluviais, pedogenizadas ou não, e a tecnogênica, haja vista que elas apresentaram classes texturais semelhantes. Isso sugere que, neste caso, a classificação textural não foi um parâmetro suficiente para distinguir as variações da fácies coluvial. Esta característica dos sedimentos mostra que, à exceção da unidade I, as demais unidades estão com propriedades texturais que diferem da isalterita do riolito e das fácies hidrotermal, sugerindo uma filiação genética da aloterita ou de horizontes pedológicos de uma ou outra fácies do substrato.

\section{Análise química total}

A análise química total foi empregada para verificar o grau de intemperismo/pedogênese do material fonte dos sedimentos das unidades litológicas da seção estudada. Os ganhos e perdas dos dez principais óxidos foram comparados com a isalterita e a rocha fresca do riolito, substrato no qual se encontram assentadas as unidades na seção HS1 (ver Figura 3).

Para a rocha fresca foram obtidos os valores $71,30 \% \mathrm{SiO}_{2}$ e $7,23 \%$ de álcalis $\left(\mathrm{Na}_{2} \mathrm{O}+\mathrm{K}_{2} \mathrm{O}\right)$ que, aplicados ao diagrama TAS, indicam que o material analisado corresponde a riolito (WERNICK, 2004) - o que se demonstra na Tabela 2. Independente da nomenclatura da rocha obtida aqui, a mesma corresponde a um derrame vulcânico ácido com baixa concentração de bases e elevado teor de silício. A partir da comparação entre os percentuais das bases da rocha fresca (total de $8,95 \%$ ) com os da isalterita (total de $0,68 \%$ ), percebemos uma redução significativa no início do processo de intemperismo (Tabela 2), devido à perda de bases da rocha já na fase inicial de individualização dos materiais intemperizados, como verificado para outras seções estratigráficas (PAISANI et al., 2014). Esta perda de bases é acompanhada pela solubilização da $\mathrm{SiO}_{2}$ que reduziu 11,36\% em 
relação à rocha fresca. $\mathrm{Já}_{\mathrm{o}} \mathrm{Al}_{2} \mathrm{O}_{3}$, apresentou ganhos relativos ao intemperismo, duplicando seu percentual.

\begin{tabular}{|c|c|c|c|c|c|c|c|}
\hline & \multicolumn{6}{|c|}{ Unidades Estratigráficas } & \multicolumn{2}{c|}{ Riolito } \\
\hline & VI & IV & III & II & I & Isalterita & $\begin{array}{c}\text { Rocha } \\
\text { Fresca }\end{array}$ \\
\hline $\mathrm{SiO}_{2}$ & 48,23 & 51,45 & 57,29 & 50,45 & 48,71 & 59,94 & 71,30 \\
\hline $\mathrm{TiO}_{2}$ & 1,48 & 1,76 & 1,32 & 1,66 & 1,14 & 1,07 & 0,71 \\
\hline $\mathrm{Al}_{2} \mathrm{O}_{3}$ & 19,82 & 23,55 & 23,43 & 24,32 & 28,90 & 23,47 & 11,64 \\
\hline $\mathrm{Fe}_{2} \mathrm{O}_{3}$ & 7,27 & 8,96 & 5,42 & 7,04 & 4,70 & 4,27 & 5,25 \\
\hline $\mathrm{MnO}$ & 0,02 & 0,02 & 0,02 & 0,02 & 0,02 & 0,02 & 0,05 \\
\hline $\mathrm{MgO}$ & 0,30 & 0,45 & 0,36 & 0,30 & 0,25 & 0,41 & 0,30 \\
\hline $\mathrm{CaO}$ & 0,05 & 0,03 & 0,03 & 0,02 & 0,03 & 0,03 & 1,42 \\
\hline $\mathrm{Na}_{2} \mathrm{O}$ & 0,02 & 0,02 & 0,02 & 0,02 & 0,02 & 0,02 & 2,39 \\
\hline $\mathrm{K}_{2} \mathrm{O}$ & 0,19 & 0,28 & 0,20 & 0,21 & 0,32 & 0,20 & 4,84 \\
\hline $\mathrm{P}_{2} \mathrm{O}_{5}$ & 0,16 & 0,12 & 0,12 & 0,12 & 0,24 & 0,21 & 0,20 \\
\hline $\mathrm{Loi}$ & 22,01 & 13,61 & 11,99 & 16,60 & 15,97 & 10,25 & 1,16 \\
\hline $\mathrm{Total}$ & 99,55 & 100,25 & 100,20 & 100,74 & 100,30 & 99,89 & 99,26 \\
\hline & & & & & & & \\
\hline $\mathrm{Ki}$ & 4,14 & 3,71 & 4,16 & 3,53 & 2,87 & 4,34 & 10,41 \\
\hline $\mathrm{Kr}$ & 3,35 & 2,99 & 3,62 & 2,98 & 2,60 & 3,89 & 8,09 \\
\hline
\end{tabular}

Tabela 2: Química analítica (percentual do óxido em peso) e os índices Ki e Kr de amostras das unidades e do riolito.

Em relação aos índices $\mathrm{Ki}$, a isalterita exibe 4,34, enquanto a rocha fresca apresenta 10,41 (ver Tabela 2). A razão entre estes valores corresponde a 0,42, que indica condições hidrolíticas de alteração (PEDRO, 1969). Em relação ao Ki das unidades estratigráficas, estes estão entre 2,87 a 4,16 (Tabela 2), o que corresponde à situação hidrolítica sialítica mista (MELFI; PEDRO, 1977), condicionada, sobretudo, pela temperatura média anual entre 16 e $23^{\circ} \mathrm{C}$ (PEDRO, 1969, op. cit.). Desta forma, é possível inferir que trata-se de materiais de solos não lateríticos (VIEIRA, 1988), diferentemente do encontrado nas demais unidades geomórficas, no setor mais a oeste da região do SW do Paraná e do NW de Santa Catarina. Por outro lado, é preciso considerar que o substrato rochoso da área é rico em $\mathrm{SiO}_{2}$ cristalizada na forma de cristobalita e quartzo, que podem contribuir para a elevação dos valores $\mathrm{Ki}$ e $\mathrm{Kr}$.

Os valores mais elevados para a relação Ki foram obtidos nas unidades III e VI e estão muito próximos do $\mathrm{Ki}$ da isalterita, sugerindo que essas unidades exibem grau de alteração menor quando comparado às demais. Essa tendência também é verificada para $\mathrm{o} \mathrm{Fe}_{2} \mathrm{O}_{3}$, cujo teor determinado foi relativamente reduzido com o início do intemperismo. Assim, como no caso do $\mathrm{Ki}$, os valores do $\mathrm{Kr}$ se mostram 
relativamente elevados seguindo a tendência do primeiro (ver Tabela 2). A unidade I exibe os menores índices de $\mathrm{Ki}$ e $\mathrm{Kr}$, correspondendo a materiais mais alterados do que os das demais unidades.

\section{Mineralogia das argilas da fração fina}

A fração fina da isalterita do riolito, além de apresentar hidróxidos de ferro, é constituída essencialmente por argilominerais do grupo da caolinita (1:1) e dois minerais primários com base de $\mathrm{SiO}_{2}$, a cristobalita e o quartzo (ver Figura 5). A agudez do pico da cristobalita sugere que tal mineral primário é predominante na fração argila, o que pode explicar os elevados valores de $\mathrm{Ki}$ e $\mathrm{Kr}$ calculados. Os baixos reflexos da caulinita mostram que este argilomineral se encontra em pequenas quantidades e está sendo gerado diretamente do intemperismo da rocha, por alteroplasmação (DELVIGNE, 1998). A ausência de argilominerais 2:1 e o predomínio da caolinita indicam que, de fato, houve um processo de monossialitização na sua formação.

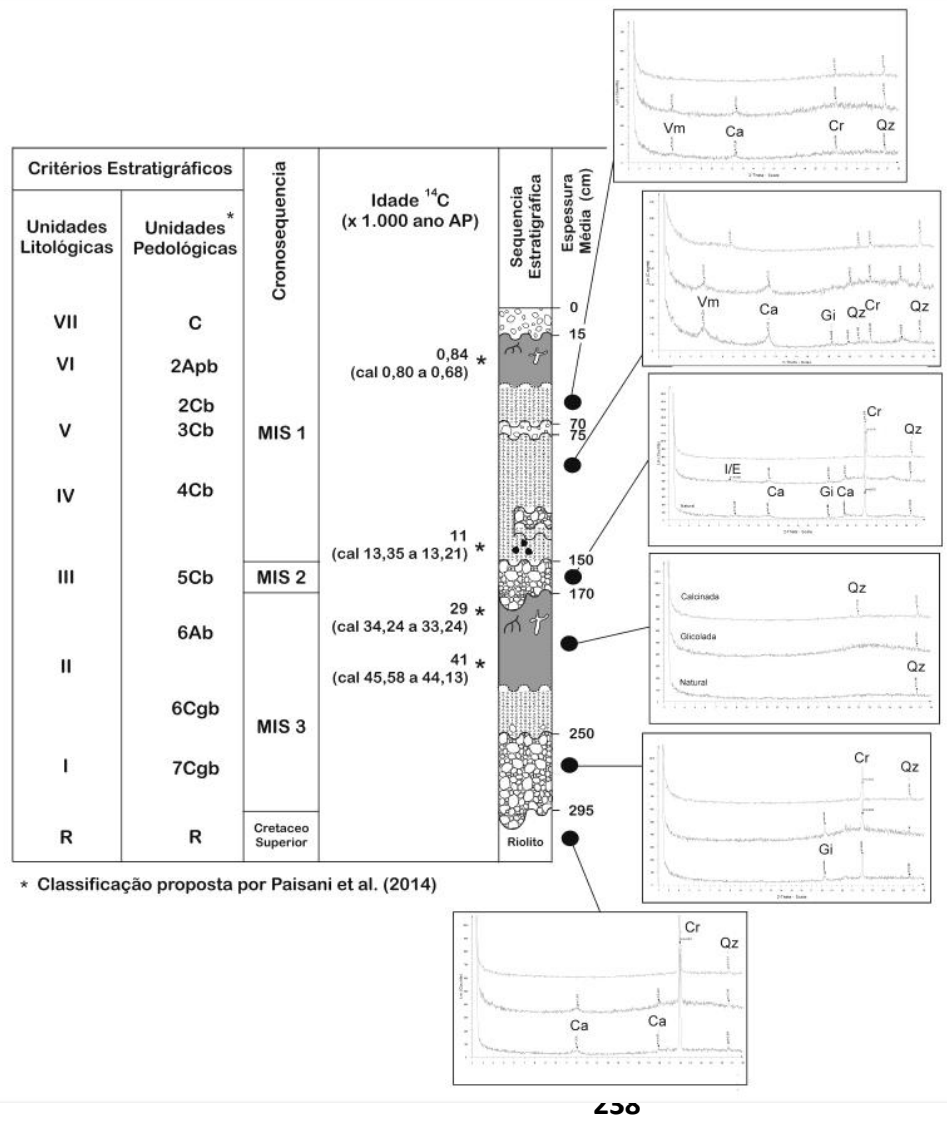

Figura 5: Difratogramas de raio-X contendo a mineralogia das argilas da fração fina das unidades estratigráficas da HS1.

Legenda: $\mathrm{Cr}$ : cristobalita. Qz: quartzo. $\quad \mathrm{Gi}$ : gibbsita. $\mathrm{Ca}$ : caolinita. Vm: vermiculita. I: ilita. E: esmectita. 
Os caminhos do intemperismo das rochas ácidas da região são pouco compreendidos. Sabe-se, até o momento, que nos riodacitos do membro Chapecó as condições ambientais - sobretudo as climáticas atuais - são responsáveis pela alteroplasmação dos fenocristais de plagioclásio, gerando minerais secundários por três caminhos: a) diretamente gibbsita, b) gel amorfo para caolinita e posteriormente para gibbsita e c) diretamente gibbsita e goetita (CLEMENTE; AZEVEDO, 2007). Nesta sequência percebe-se que a alitização é o processo predominante. Considerando os resultados obtidos para a seção HS1, verifica-se que a isalterita do riolito da área em estudo se encontra na fase intermediária, entre o gel amorfo e a gibbsita descrita por Clemente e Azevedo (2007). Entretanto, esse estágio de alteração expressa o ambiente hidromórfico desenvolvido no paleofundo de vale onde se estabeleceu a seção da área de estudo.

Em relação à fácies hidrotermal do substrato rochoso, suas propriedades foram estudadas com maior detalhe por Lima (2013). Há dois níveis com propriedades diferentes, o nível 1 - mais representativo desta fácies (ver Figura 2) -, que exibe baixos reflexos de esmectita e reflexos agudos de ilita e quartzo. E o nível mais delgado, situado no contato onde o riolito apresentou minerais primários - como cristobalita e quartzo - e argilominerais com baixíssimos reflexos de caolinita (1:1) e interestratificação da ilita/esmectita (2:1). A caolinita é o argilomineral mais comum tanto como produto residual do intemperismo supérgeno, quanto do hidrotermal (TARDY, 1993). No presente caso, o importante é notar que a caolinita se encontra desordenada e em quantidades reduzidas. Já em relação à presença de interestratificações da ilita/esmectita, é de se pensar em um material em estágio inicial de alteração com a esmectita sendo ilitizada. Este fenômeno de interestratificação é complexo e tem sido admitido como uma fase final de uma série de reações geoquímicas, em tempos curtos ou longos, geradas por intemperismo supérgeno, hidrotermal, diagênese, dentre outras possibilidades (MOORE; REYNOLDS JR, 1997).

Em relação às unidades estratigráficas, destacam-se os resultados da mineralogia da matriz da unidade I - fácies aluvial, que apontam à cristobalita e à gibbsita como componentes básicos, como se verifica na Figura 5. A gibbsita corresponde ao material de coloração esbranquiçada da matriz dessa unidade, facilmente reconhecida em campo. Verifica-se aqui a ação da alitização - hidrólise total. Diante disso, duas possibilidades surgem para explicar a ausência de outros argilominerais no material fonte: a) material pedológico em avançado estágio de alteração; b) material proveniente da isalterita do riolito, onde ocorrerá a alteração direta do plagioclásio para gibbsita, como colocado por Clemente e Azevedo (2007) e c) perfis de intemperismo em diferentes estágios de evolução.

Para analisar tais hipóteses, devemos considerar as características gerais da unidade estratigráfica. Esta corresponde a conglomerados com clastos suportados, 
sobretudo seixo médio, constituídos de fragmentos líticos de riolito (PAISANI et. al., 2012). Sua matriz também exibe fração grossa, com destaque para a areia de muito fina a fina que a constitui, dentre outros minerais, por cerca de 5 a $14 \%$ de feldspato (ver as Tabelas 3 e 4), possivelmente plagioclásio. Comparando tais características com os constituintes da fração argila, percebe-se que se trata da mistura de materiais gerados em dois perfis de intemperismo distintos. Um deles com o predomínio da desagregação física, no ambiente ortomórfico (solo Litólico) disponibilizando os feldspatos para transporte superficial; e outro com clastos gerados pela alteração diferencial em perfil de decomposição química.

\begin{tabular}{|c|c|c|c|c|c|c|c|}
\hline Constituinte & \multicolumn{7}{|c|}{ Frações Granulométricas (\%) } \\
\hline & AMF & AF & AM & AG & AMG & Gr & Sx \\
\hline Calcedonia & 95 & 97 & 8 & 82 & 24 & 41 & 29 \\
\hline Feldspato & 3 & 2 & - & - & - & - & - \\
\hline Quartzo & 1 & 1 & - & 12 & - & - & - \\
\hline Litorrelíquia & 1 & - & 92 & 6 & 76 & 59 & 71 \\
\hline N Grãos $^{\circ}$ & 100 & 180 & 100 & 150 & 101 & 17 & 7 \\
\hline
\end{tabular}

Tabela 3: Constituintes da fração grossa da base da unidade I (aluvial).

Legenda: $\mathrm{AMF}=$ areia muito fina $(0,062-0,124 \mathrm{~mm}) . \mathrm{AF}=$ areia fina $(0,125-0,24 \mathrm{~mm}) . \mathrm{AM}=$ areia média $(0,25-0,49 \mathrm{~mm}) . A G=$ areia grossa $(0,5-0,9 \mathrm{~mm}) . A M G=$ areia muito grossa $(1-2 \mathrm{~mm}) . \mathrm{Gr}=$ grânulo (2,1-4 mm). Sxf = seixo fino (4,1-8 mm). $\mathrm{N}$ = número de grãos analisados.

\begin{tabular}{|c|c|c|c|c|c|c|c|}
\hline \multirow{2}{*}{ Constituinte } & \multicolumn{7}{|c|}{ Frações Granulométricas (\%) } \\
\cline { 2 - 8 } & AMF & AF & AM & AG & AMG & Gr & Sx \\
\hline Calcedônia & 88 & 95 & 62 & 53 & 64 & 20 & - \\
\hline Feldspato & 10 & 4 & - & - & - & - & - \\
\hline Quartzo & 2 & 1 & 16 & 29 & 05 & - & - \\
\hline Litorrelíquia & - & - & 22 & 38 & 31 & 80 & 100 \\
\hline N $^{\circ}$ Grãos & 100 & 100 & 100 & 103 & 87 & 10 & 1 \\
\hline
\end{tabular}

Tabela 4: Constituintes da fração grossa do topo da unidade I (aluvial).

Já comparando as unidade I e III - fácies aluvial - percebe-se na última significativas diferenças (Figura 5), como a menor quantidade de gibbsita, a presença de caolinita (1:1) e interestratificação da ilita/esmectita $(2: 1)$ em pequenas quantidades. Na unidade III, com exceção da gibbsita, a constituição do material está muito próxima daquela do nível 2 do substrato fácies hidrotermal, podendo ser derivada desse material em um estágio de alteração posterior quando o substrato esteve exposto à superfície, submetido a alteração supérgena. Aqui também se percebe mistura de materiais distintos, porém, difere-se da unidade I por apresentar clastos que caracterizam um material conglomerado provavelmente gerado no perfil de alteração do riolito (monossialitização supérgena) e uma matriz derivada da fácies hidrotermal do substrato. 
As propriedades da fração fina da unidade II, fácies coluvio-aluvial pedogenizada, destoa em relação às demais (Figura 5), pois não exibe argilominerais e apresenta apenas quartzo, em pouca quantidade. A mesma é constituída essencialmente por quartzo, hidróxidos e óxidos de ferro, além de matéria orgânica. A ausência de argilominerais decorre de condições ambientais específicas que teriam favorecido as condições de acidólise de forma parcial (MELFI; PEDRO, 1978; KER; RESENDE, 1990). Considerando as circunstâncias nas quais se encontravam a unidade II na época de sua pedogenização - ambiente hidromórfico de fundo de vale sujeito à sazonadidade hídrica em clima de altitute (PAISANI et al., 2012) - pode-se admitir que tal característica não foi herdada da área fonte, mas, sim, da matriz da unidade que chegou a tal estágio posteriormente à sua sedimentação, diante de uma acidólise (parcial), como sugerido por Paisani et al. (2014) para paleossolos correlatos na área de estudo.

Na unidade IV, fácies coluvial, a cristobalita voltou a ser encontrada, porém em menores quantidades comparadas às fácies aluviais (ver Figura 5). Nesta unidade registra-se gibbsita, caolinita (1:1) e vermiculita (2:1). Os reflexos das duas últimas são médios e largos, sugerindo que tais argilominerais se encontram em significativas quantidades, porém desestruturados. As propriedades da fração fina dessa unidade sugerem que o material originário já estava sobre a influência da pedogênese em outra fase geoquímica. O material mantém os produtos da alteroplasmação, seguindo o caminho colocado por Clemente e Azevedo (2007) da passagem da formação de caolinita para gibbsita, bem como a sialitização mista, gerando vermiculita e caolinita neoformada. Assim, registra-se a passagem de duas tendências, tanto a sialitização quanto a alitização, com o predomínio da primeira.

A alteroplasmação gerando gibbsita ou caulinita, hidrólise parcial para total, não estava ocorrendo com tanta intensidade como à época de formação da fração argila do material fonte dessa unidade. Naquela época, a hidrólise parcial poderia estar ocorrendo para possibilitar a geração da vermiculita por caminhos do intemperismo, que também estavam associados à alteração do plagioclásio mineral mais frequente. Embora interpretações paleoclimáticas a partir dos argilominerais constituintes de unidades sedimentares devam ser feitas com cautela (SINGER, 1979/80; 1984), estes constituintes revelam que o produto do intemperismo da área fonte dos sedimentos da unidade IV eram diferentes daqueles observados por Clemente e Azevedo (2007 op. cit.) em condições atuais. Levandose em consideração que o paleoperfil de alteração que forneceu os materiais para a unidade IV se desenvolveu por cerca de 30.000 anos, entre os estágios isotópicos 3 e 2 (PAISANI et al., 2012), a mudança de processo geoquímico constatado pode representar a variação climática registrada na passagem entre os estágios isotópicos. Enquanto as condições climáticas do primeiro eram similares às atuais (EIM 1), relativamente frio e úmido, as do segundo deveriam ser mais frias, porém mais secas, se comparadas ao o clima atual. Nessas condições, os ácidos orgânicos 
estariam em menor quantidade para o intemperismo, o que justificaria a atuação de hidrólise parcial. Tal situação pedogeoquímica é correlata à verificada para Latossolos da superfície geomórfica 6 e sugere mudança de processo pedogeoquímico de mossialização para bissialitização durante o Último Máximo Glacial no Planalto das Araucárias (PAISANI et al., 2013a).

A unidade VI, coluvial pedogenizada, se assemelha à unidade anterior, registrando vermiculita, caolinita e os minerais primários cristobalita e quartzo (ver Figura 5). Difere-se apenas da unidade IV, por apresentar menores quantidades de vermiculita e de caolinita e ausência de gibbsita. Tais características apontam para um material em estágio inicial de alteração em condições ambientais favoráveis à mudança de processo pedogeoquímico de mossialização para bissialitização, similar ao material verificado na unidade IV. Na unidade VI, a pedogênese registrada nos aproximadamente 1.000 anos AP (PAISANI et al., 2012 op. cit.) não foi suficiente para apagar tais registros e restabelecer os caminhos de alteração apontados por Clemente e Azevedo (2007). A constituição dos argilominerais da unidade VI é similar à da unidade anterior.

\section{Conclusão}

$\mathrm{Na}$ tentativa de reconstruir paleoperfis de intemperismo a partir dos sedimentos de depósito de articulação encosta/calha fluvial no Planalto de Palmas/Água Doce durante os 41.000 anos AP., a abordagem metodológica mostrou que: a) a classificação textural da matriz das unidades estratigráficas, exceto da unidade I aluvial -, mostra-se diferente da matriz da isalterita do riolito e da fácies hidrotermal, sugerindo que seus materiais correspondiam a produtos da pedogênese ou aloterita; b) a análise química total revelou que o riolito é pobre em bases e que a sua isalterita, fase inicial de intemperismo, apresenta significativas perdas de $\mathrm{SiO}_{2}$ e ganhos de $\mathrm{Al}_{2} \mathrm{O}_{3}$; cujos índices $\mathrm{Ki}$ e $\mathrm{Kr}$ não se mostraram úteis para a análise feita neste trabalho, face o elevado teor de $\mathrm{SiO}_{2}$ cristalina; e c) os produtos do intemperismo, fração argila, trouxeram os principais resultados dos paleoperfis de intemperismo nas áreas fontes dos materiais das unidades estratigráficas da área em estudo.

A aloterita do riolito registra o paleoambiente hidromórfico, fundo de vale de canal de segunda ordem, cujo processo de alteração foi a monossialitização, estando em conformidade com os processos geoquímicos atuais (Figura 6). A unidade I - conglomerado aluvial com clastos suportados - tem uma matriz constituída de diferentes materiais gerados em perfis de intemperismo distintos. Um deles com o predomínio da desagregação física, disponibilizando os feldspatos para transporte superficial; e outro com clastos gerados pela alteração diferencial em perfil de decomposição química comandado pela alitização. Tais perfis 
representam dois ambientes distintos, um hidromórfico e outro ortomórfico com solo Litólico. A época de formação desses perfis de intemperismo não pode ser estabelecida considerando a cronologia do registro estratigráfico (Paisani et al.,

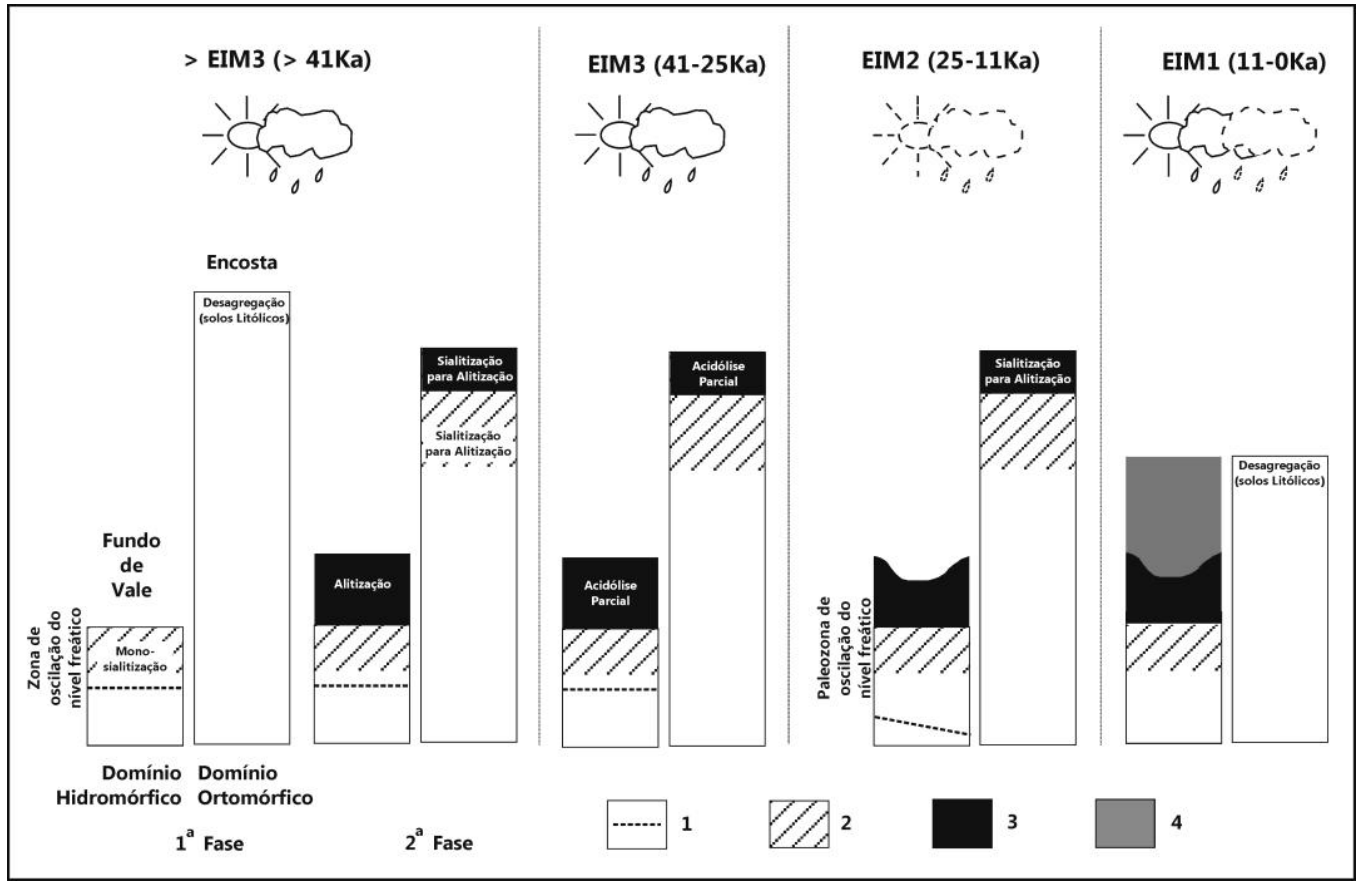

2012). Sabe-se, apenas, que tais perfis de intemperismo foram gerados antes de 41.000 anos AP (Figura 6).

Figura 6: Reconstrução dos perfis de intemperismo e inferência paleoclimática da época de sua formação. O declínio do nível freático deve-se ao clima mais seco no MIS 2 e mudanças de nível de base (PAISANI et al., 2014). As linhas descontínuas sugerem condições climáticas mais frias e menos úmidas. 1: nível freático. 2: alterita (aloterita + isalterita). 3: solum. 4: colúvios.

A unidade II - colúvio pedogenizado -, Neossolo flúvico à época, apresenta fração fina constituída exclusivamente por quartzo. A ausência de argilominerais mostra que a matriz da unidade chegou a tal estágio de evolução intempérica posteriormente à sua sedimentação diante da acidólise parcial (Figura 6). Essas condições perduraram, sobretudo, durante a máxima concentração de ácidos orgânicos, no EIM 3 - entre 41 e 25.000 anos AP. Durante esta fase as encostas exibiam perfis de intemperismo caracterizados pela sequência de níveis contendo o solum - horizontes A e B - e a alterita - constituída pela aloterita e isalterita como mostra a Figura 6. Os argilominerais da unidade IV sugerem que nessa fase ocorria a passagem da monossialitização para a alitização, sobretudo na isalterita. Com a mudança climática para o EIM 2, último máximo glacial, as condições hídricas 
afetaram a produção de ácidos orgânicos provocando mudança no processo geoquímico, estabelecendo a bissialitização na isalterita e mantendo a passagem da monossialitização para alitização no solum (Figura 6).

Durante o EIM 2 estabeleceu-se a unidade III, aluvial, caracterizada pela mistura de materiais de diferentes fontes, seixos provindos de perfil de alteração do riolito e a matriz provinda da alitização supérgena da fácies hidrotermal do substrato, ambos gerados no EIM 3. Na sequência estratigráfica registra-se justamente a inversão dos materiais intemperizados, com o estabelecimento de nível menos intemperizado sobre aqueles do solum gerado nas encostas antes da passagem para o EIM 1, como evidencia a fração fina da unidade VI.

Em síntese, têm-se quatro momentos distintos de intemperismo na área de estudo: a) antes de 41.000 anos AP, se desenvolveram dois momentos ainda não identificados - um de monossialitização e outro de alitização; b) entre 41.000 e 25.000 anos AP, registra-se a passagem para acidólise; c) entre 25.000 e 11.000 anos AP houve mudança de processo, retornando à hidrólise; e d) nos últimos 11.000 anos os materiais mantiveram o registro geoquímico das fases anteriores.

\section{Agradecimentos}

Ao CNPq (Proc. 300530/2012-9), à Fundação Araucária/ SETI/ Gov.Paraná (Convênio n. 204/2012) e à CAPES/CNPq - PVE (Projeto 144/2012).

\section{Bibliografia}

ALMEIDA, F. F. M. (1956) O Planalto basáltico da Bacia do Paraná. Boletim Paulista de Geografia, 24. pp. 3-34.

CLEMENTE, C. A.; AZEVEDO, A. C. (2007) Mineral weathering in acid saprolites from subtropical, Southern Brazil. Scentia Agricola, 64 (6). pp. 601-607. CHMYZ, L. (2013) Aspectos vulcanogênicos das rochas ácidas do Tipo Palmas da província magmática do Paraná aflorantes no Sudoeste Paranaense. Dissertação (Mestrado em Geologia), Universidade Federal do Paraná.

DELVIGNE, J. E. (1998) Atlas of micromorphology of mineral alteration and weathering. The Canadian Mineralogist. Special Publication 3, ORSTOM.

FLEMMING, B.W. (2000) A revised textural classification of gravel-free muddy sediments on the basis of ternary diagrams. Continental Shelf Research, 20. pp. 1125-1137.

GERRARD, J. (1992) Soil geomorphology - an integration of pedology and geomorphology. Champman \& Hall. 
GHIBAUDO, G. (1992) Subaqueous sediment gravity flow deposits: practical criteria for their field description and classification. Sedimentology, 39. pp. 423454.

GUERRA, S.; PAISANI, J. C. (2012) Levantamento estratigráfico das formações superficiais cenozoicas no Planalto de Palmas (PR) e Água Doce (SC): subsídio ao estudo da evolução da paisagem a partir do Estágio Isotópico Marinho 3. Revista Ambiência, 8 (Esp.). pp. 651-665.

. (2013) Abrangência espacial e temporal da morfogênese e pedogênese no Planalto de Palmas (PR) e Água Doce (SC): subsídio ao estudo da evolução da paisagem quaternária. Geociências, vol. 32, UNESP. pp. 501-515.

LIMA, J. G. G. (2013) Ocorrência e gênese de derrame alterado sob rocha sã no Planalto de Palmas (PR)/Água Doce (SC). Dissertação (Mestrado em Geografia), Universidade Estadual do Oeste do Paraná.

MELFI, A. J.; PEDRO, G. (1977) Estudo geoquímico dos solos e formações superficiais do Brasil. Parte 1 - Caracterização e repartição dos principais tipos de evolução pedogeoquímica. Revista Brasileira de Geociências, 7. pp. 271-286.

(1978) Estudo geoquímico dos solos e formações superficiais do Brasil. Parte 2 - Considerações sobre mecanismos geoquímicos envolvidos na alteração superficial e sua repartição no Brasil. Revista Brasileira de Geociências, 8. pp. 1122.

MOORE, D. M.; REYNOLDS JR, R. C. (1997) X-ray diffraction and the identification and analysis of clay minerals. Oxford University Press, $2^{\text {nd }}$ ed.

NARDY, A. J. R.; MACHADO, F. B.; OLIVEIRA, M. A. F. (2008) As rochas vulcânicas mesozóicas ácidas da Bacia do Paraná: litoestratigrafia e considerações geoquímico-estratigráficas. Geociências, vol. 38 (1), UNESP. pp. 178-195.

PAISANI, J. C.; GEREMIA, F. (2010) Evolução de encostas no Planalto Basáltico com base na análise de depósitos de colúvio - médio vale do rio Marrecas, SW do Paraná. Geociências, vol. 29 (3), UNESP. pp. 321-334.

PAISANI, J. C.; PONTELLI, M. E.; ANDRES, J. (2008) Superfícies aplainadas em zona morfoclimática subtropical úmida no Planalto Basáltico da Bacia do Paraná (SW Paraná/ NW Santa Catarina): primeira aproximação. Geociências, vol. 27 (4), UNESP. pp. 541-553.

PAISANI, J. C.; CALEGARI, M. R.; PONTELLI, M. E.; et al. (2013a) O papel das mudanças climáticas do Quaternário Superior na dinâmica evolutiva de paleovale de segunda ordem (Sul do Brasil). Revista Brasileira de Geomorfologia, 14. pp. 103-116.

PAISANI, J. C.; PONTELli, M. E.; CORRÊA, A. C. B.; RODRIGUES, R. A. R. (2013b) Pedogeochemistry and micromorphology of oxisols - a basis for understanding etchplanation in the Araucárias Plateau (Southern Brazil) in the Late Quaternary. Journal of South American Earth Sciences, 48. pp. 1-12. 
PAISANI, J. C.; PONTElli, M. E.; CALEGARI, M. R. (2012) Evolução de bacias de baixa ordem nos 41.000 anos AP - Brasil Meridional. Mercator, 11 (26), UFC. pp.131-148.

PAISANI, J. C.; PONTELLI, M. E.; OSTERRITH, M. L.; et al. (2014) Paleosols in low-order streams and valley heads in the Araucaria Plateau - record of continental environmental conditions in southern Brazil at the end of MIS 3. Journal of South American Earth Sciences, 54. pp. 57-70.

PEDRO, G. (1969) A alteração das rochas em condições superficiais (perimorfismo) - caracterização geoquímica dos processos fundamentais. Notícias Geomorfológicas, 9 (17). pp. 3-14.

PONTELLI, M. E.; PAISANI, J. C.; LIMA, J. G. G. (2011) Distribuição de volumes pedológicos em vertente de superfície geomorfológica em elaboração Planalto Basáltico da Bacia do Paraná. Anais..., XIV Simpósio de Geografia Física Aplicada, p.11, CD-Rom.

RETALLACK, G. J. (1997) A colour guide to paleosols. John Wiley \& Sons. RODRIGUES, R.A.R. (2011) Estágio de intemperismo de perfil laterítico em área subtropical com substrato basalto - superfície aplainada VI (SW PR). Dissertação (Mestrado em Geografia), Universidade Estadual do Oeste do Paraná - Francisco Beltrão.

KER, J. C.; RESENDE, M. (1990) Caracterização química e mineralógica de solos brunos subtropicais do Brasil. Revista Brasileira de Ciências de Solo, 14. pp. 215225.

SCHNEIDER, R. L.; MUHLMANN, H.; TOMMASI, E.; et al. (1974) Revisão estratigráfica da Bacia do Paraná. XXVIII Congresso Brasileiro de Geologia, Anais..., Porto Alegre. pp. 47-65.

SINGER, A. (1979/80) The paleoclimatic interpretation of clay minerals in soils and weathering profiles. Earth-Science Reviews, 15. pp. 303-326.

. (1984) The paleoclimatic interpretation of clay minerals in sediments - a review. Earth-Science Reviews, 21. pp. 251-293.

SUGUIO, K. (1973) Introdução à sedimentologia. São Paulo: Edgard Blücher/EDUSP.

TARDY, Y. (1993) Pétrologie des laterites et des sols tropicaux. Paris: Masson. THOMAS, M. F. (1994) Geomorphology in the tropics: a study of weathering and denudation in low latitudes. John Wiley \& Sons.

VIEIRA, L. S. (1988) Manual da ciência do solo com ênfase aos solos tropicais. 2ed. São Paulo: Ed. Agronômica Ceres.

WERNICK, E. (2004) Rochas magmáticas: conceitos fundamentais e classificação modal, química, termodinâmica e tectônica. São Paulo: Ed. UNESP. 